\title{
Cooperation for Innovation and Exchange of Good Practices in Human Capital Management
}

\author{
Angela-Eliza MICU ${ }^{\star}$, Ramona Valentina NECULA ${ }^{\star \star \star}$
}

\begin{tabular}{l}
\hline \multicolumn{1}{c}{ A R T I C L E I N F O } \\
\hline Article history: \\
Accepted June 2019 \\
Available online August 2019 \\
\hline JEL Classification \\
J24, J18, 03, J81, J83 \\
Keywords: \\
Human capital, \\
Public policy, \\
Innovation \\
Working conditions \\
Workers' Rights
\end{tabular}

\begin{abstract}
A B S T R A C T
Globalization, sustainable development, fierce competition, rapid evolution in technology and communications have created social pressure to drive organizations to innovation. In this context, a successful manager must theoretically master the notions of human capital management, innovation management, talent management, cooperation management, performance management and, last but not least, managerial psychology. Juggling with the exposed notions should be complemented by a practice that will generate useful results both for the organization and for society. In our paper, we aim to identify the extent in which cooperation through experience exchanges and internships influences the management of human capital, while emphasizing the similarities and differences, both organizationally and culturally, between the Romanian institutions and the European institutions.
\end{abstract}

(C) 2019 EAI. All rights reserved.

\section{Introduction}

In the current context of globalization, sustained by sustainable development, the current society, called "knowledge-based", is more than an informational society, imprinted on both technology and information that travels at an unimaginable speed, as well as the importance to human capital and its management.

Looking at things from this perspective, the managerial act is a particularly complex one, and the management of organizations is challenged in the sense of alignment with the standards imposed by the current society.

Under these circumstances, the managerial act itself is a challenge, with multiple reasons leading to failure. To avoid this, managers need to master theoretical notions and apply strategies specific to human capital management, international management, conflict management, cooperative and innovation management and, last but not least, managerial psychology and talent management to cope with pressure competition generated by the phenomenon of globalization.

At European level, one of the key issues is to harmonize European construction with the interests, specific aspirations of each nation, which can not be conceived without international co-operation.

Similarly, on an organizational scale, the managerial act involves reconciling the interests and aspirations of the employees with the organization's objectives and the mission declared publicly by the organization.

The dynamics of employee identities and interests must be very well coordinated from the point of view of management, so that employees"s personal space not to be violated, as well as the balance and harmony of their organization not to be affected. In this context, the manager has to learn to be a master, to handle the art of cooperation, the creativity and initiatives, and also a limit imposed by the organizational specificity.

\section{Literature review}

Indutably, in any organization, people are very important, regardless of the position they occupy. „Each element in the organization is modeled by the presence and ideas of those with decision-making power. [...] But not only leadership ensures the specificity of an organization, but also every member. Through his talent, knowledge and vocation, any individual in the organization puts his mark on the part he controls. When decisions are made, when a change of any kind is desired, account is taken of the presence of man, his attitudes and values. Even if an organization does not exist for the needs of its members, people have 
to occupy the first place, otherwise the whole structure is not the foundation"(Pinte, 2003).

An organization can be successful if its management is intelligent and employees are sufficiently involved and willing to dedicate good organizational action. Thus, things could not work without the cooperation of the members of the organizations, regardless of their status and functions. „Cooperation is one of the most important themes for modern organizations. Cooperation as a synergistic force is a core organizational process driving organizational effectiveness.[...] It is often the quality of cooperation that distinguishes successful from less successful organizations. Therefore, managers are challenged to foster cooperation within the company to ensure that: the company is able to quickly adapt to changes in the environment; the company is well positioned in inter-organizational networks; and that flexibility in production or services is assured to cope with changes in the environment" (Schalk \& Curșeu, 2010).

The majority of literature authors consider that cooperation is a process in which individuals and / or organizations interact, forming mutually advantageous relationships. Thus, there are three distinct concepts of cooperation: people who work together to achieve a common goal; interdependent agents of objectives involved in social interactions; and individual actions that maximize collective earnings and mutual benefit.

The issue of cooperation can be dealt with at micro-organizational level, but also at macro level: regional, national, international, in the sense that we are discussing organizational goals or much broader objectives and more complex issues at global level. For example, if at an organizational level we are confronted with the financial problems related to wage increases and the provision of better working conditions, at European or even modal level, we are experiencing poverty. „Development cooperation has been part of the process of European integration at the outset. [...] In addition, in 2000, the EU committed itself to supporting the United Nations Millennium Development Goals, and the Lisbon Treaty further strengthened the legal basis for EU development cooperation. It clearly states that poverty reduction and eradication are the main objectives of the Union's policy on development cooperation" (EU, 2014).

Cooperation is in fact helpful, but also learning from each other. People can learn very easily by cooperating in achieving common goals, seeking mutual benefits in the end. In this process, we reiterate the importance of quality human resources and a very good human capital management. „Human capital is generally understood to consist of the individual's capabilities, knowledge, skills and experience of the company's employees and managers, as they are relevant to the task at hand, as well as the capacity to add to this reservoir of knowledge, skills, and experience through individual learning" (Stiles \& Kulvisaechana). In this context, the recommendations of the European Commission in the field of human capital management, which illustrate, , at least at the theoretical level, a model of mamangement of human capital that includes, above all, labor force planning" (Sienkiewicz, 2018).

Regarding the last point highlighted in the previous paragraph, we are discussing an ambitious, longterm approach so as to ensure that people acquire the skills they need to learn through their studies and prosper both in the labor market, as well as in society in general. So, „other work in progress at EU and national level will also help advance this Skills Agenda, increasing people's learning opportunities and making sure that education and training is fit for purpose in the 21st century. A particular effort is needed to help bridge the gap between education and training and the labour market. We need to further invest in the modernisation of VET (vocational education and training) and higher education, and fully exploit their potential as drivers for regional development" (EU Commission, 2016).

The cooperation must be carried out definitely in all areas and specific activities (education, scientific research, organizational culture) and especially in the field of innovation. „Cooperation in innovation activities can be thought of as a trade-off between spillovers: firms generate and receive spillovers to and from their cooperation partners. [...] In order to do this, firms must try to increase the extent of incoming spillovers by investing in "absorptive capacity" (Faria, Lima, \& Santos, 2010).

The concept of innovation is, undoubtedly, part of the human capital management and defines more pretentiously the "introduction of the new". The relevance of the need for innovation within the organizational framework is explained by the many transformations due to increased competition, the galloping evolution of technical progress, the development of information technologies and, last but not least, globalization in general.

From this perspective, in recent years, literature has shown an increased interest in the issue of innovation management, as a distinct field of performance management. In this regard, we emphasize that innovation is a controllable force, closely linked to inspiration and creativity, in organizations where a perfected management has put its mark on.

"Open innovation is collaborative by definition, it is based on complex interactions of organizations with other" actors "of the socio-economic system - firms, universities and research institutes, financiers, etc. As a result, organizations' innovation outcomes increasingly depend on the structures and mechanisms created at national level to support innovation, which are components of the national innovation system "(Popescu, 2016).

There is a widespread belief that both the survival and the success of an organization depend on the efforts, behaviors and interactions of employees when they work together to fulfill the organization's mission. 
The literature in the field of human resources stipulates that „companies can effectively influence the interactions, behaviors, and motivation of employees through different human resource practices" (Collins \& Smith, 2006).

Public organizations, public services in general face the need for innovative practices and products for both their own employees and external clients in our case. Thus, the new knowledge acquired through lifelong learning (both in state-based education and training programs and in internships) is confronted with the scientific perspectives revealed with the support of research infrastructures.

Looking at things in this way, we emphasize the need to optimize the link between scientific knowledge and the organization of innovation, since exploration based on curiosity, without exploring and interpreting the results, would be useless in favor of one's own organization. That is why a change of mentality and management culture in general is needed. „All stakeholders should be better informed on, and more aware of, the existing potential for cooperation” (Infrastructures \& Group, 2018).

Today's society is also called the knowledge society, a context in which we can automatically discuss knowledge-based organizations in which the following processes are completed: assimilation of new knowledge, interaction and cooperation with both the interior and the outside of the organization, such as and innovation - the creation of new knowledge.

In close connection with the above-mentioned elements, the literature introduces the concept of knowledge management. In order to understand the notion of knowledge management, the fundamental idea of the concept of knowledge needs to be examined and understood, because the perceptions of experts and researchers are different. „Broadly, the knowledge concept is debated between two main groups: objectivists and those who adopt "epistemology of practice" (El-Farr \& Hosseingholizadeh, 2019). Despite their views, we can conclude that the theoretical and practical knowledge cannot be dealt with separately by the person holding the information and the "know-how", which is why management must properly operate with these issues.

\section{Collection of Data}

The applied questionnaire also includes an introductory part, like a brief explanatory letter, through which respondents are provided with information on the role of the survey, the purpose and objectives, and how to use the results. In this respect, we have considered in our research two general objectives, namely:

* Identify the extent to which exchanges of experience and internships influence the management of human capital;

* identifying similarities and differences both in organizational and organizational cultures, between Romanian institutions and European institutions;

as well as four specific objectives:

\# perceptions about citizens' trust in public institutions (also from a comparative point of view);

* establishing a correlation between the existence of the Code of Ethics and Professional Conduct and the system of motivation / disciplinary or dismissal procedures;

* evaluation of the extent to which employees consider themselves "happy at work" (comparative study of Romanian employees versus foreign employees);

* identifying the extent to which computerization limits bureaucracy in public interest institutions.

The questionnaire contains a total of 17 questions (of which 8 simple and 9 complexes) submitted in writing to the subjects. In constructing the questions, a number of criteria have been taken into account, such as: relevance (these have been correlated with the theme and have a particular importance for the research objectives), symmetry (each question refers to a particular aspect of the research, which is classified as unique) and clarity (the questions were formulated clearly and precisely).

More specifically, the questionnaire was applied to 40 respondents, coming from Romanian public institutions (from the Mayoralties, administrative-territorial units and County Councils).

Considering the quality of the respondents, we emphasize that the questionnaire used was a factual, administrative type.

In general, we could say that the analysis undertaken to interpret the questionnaire falls within the scope of interpretative phenomenological methods, in that it is based on the investigation of the reflection of reality in the human consciousness, by studying the way respondents perceive reality, attributing at the same time a meaning of the experiences of living. The characteristic of the interpretation is to acknowledge the role of the researcher in discovering the meaning of the respondents' experience.

\section{Data Analysis and Results}

Taking into account all the aspects mentioned earlier in the paper, in order to interpret the answers to the questionnaire referred to in the previous subchapter, based on the 17 questions, we conceived a series of hypotheses and extracted a series of conclusions.

The interviewees were asked to mention whether they had done internships or exchanges of experience in European institutions, or whether they were part of the team to implement any project in partnership with similar institutions in the European Union or any other country on globe. Of the total of 40 
respondents, 18 said they did not have such experiences, which means that only 24 questionnaires and $55 \%$ of the questionnaires were valid for interpretation.

From the answers we could see that for the most part the international experience was aimed at the European Union (most respondents traveling to Belgium, Italy and Great Britain, but also in other countries like Sweden, Malta, Ireland, Iceland, Slovenia, the Czech Republic, France, the Netherlands, Bulgaria, Poland and Spain). Only one respondent said he had practiced outside the European borders, namely in Japan.

The hypothesis no.1 was conceived as follows: "From my point of view, I have perceived the degree of trust of the citizens vis-à-vis the external public institution in which I have practiced the exchange / experience exchange as a high one."

In interpreting the answers, in order to determine the truth of the hypothesis, we used the Likert scale, often used in psychometry for the measurements made using the questionnaires. The scale is named by its inventor, the psychologist Rensis Likert, being a nominal scale of 5 values, on which we have introduced a relationship of order as follows:

Table.1. Respondents' attitude towards regarding the degree of trust of citizens in public institutions

\begin{tabular}{|c|c|c|c|c|}
\hline Totally agree & Agree & $\begin{array}{c}\text { Somewhat agree } \\
\text { Partial agreement }\end{array}$ & $\begin{array}{c}\text { Partial } \\
\text { disagreement }\end{array}$ & Totally disagree \\
\hline 1 & 2 & 3 & 4 & 5 \\
\hline
\end{tabular}

Analyzing respondents' responses, it was found that the hypothesis was confirmed. We also add that there were no opposing respondents (no 3,4,5 elements) and there were 5 respondents who even checked the very high confidence level, only 3 respondents saying they did not succeed to draw up an opinion on this issue.

It is very important, from our point of view, that the high trust in public institutions has been confirmed both in the highly developed and the least developed European countries.

The second hypothesis analyzed using the same scale as Table 1 was stated as follows: "We have perceived the interpersonal relationships within the external organization with which we have collaborated as harmonious, noting that even the hierarchical subordination relationships were cordial. "

Analyzing the answers provided in the questionnaire, the hypothesis was confirmed. We could draw one of the following conclusions: whether the Romanian employees were lucky to collaborate with foreign organizations that can represent examples of good practice for the Romanian organizations, or whether the European public institutional system works properly from the point of view of resources human and quality of services offered to citizens (resulting from the high degree of trust in the respective public institutions).

The rationality of our behavior as employees is governed by a set of rules or rules, more or less contoured, reflecting what is right or unfair, moral or immoral, lawful or unlawful, right or wrong, and which set the permissive area of individuals' actions within organizations. In this respect, hypothesis 3 was conceived: "We have found that in the institution where we have done the internship / exchange of experience the Code of Ethics and Professional Conduct is given greater importance to the institution where I work in Romania, while observing differences in complaints, disciplinary, incompetence or redundancy procedures. "

Given that the questions were open to respondents requesting them to fill in the dotted delineated spaces, and given the manner of each and every vocabulary used and the vocabulary used, in interpreting the results, we have appealed to a very simple scale about the attitude shown in this statement by combining the answers to two different questions (especially formulated without an apparent link between them, other questions being intercalated to ensure the sincerity of the answers):

\section{very favorable $\quad+3+2+1+0,-1+2-3$ very unfavorable \\ The zero point $(0)$-the neutral attitude to the hypothesis assertion}

Figure no.1. Perception of the importance of codes of ethics and professional conduct Source: Own research of the authors

Using practically the specific method of analyzing the thematic-categorical content, focusing on the predominant language elements, we assessed the degree of intensity. Thus, we had the opportunity to explain the direction (neutral, favorable or unfavorable attitudes) regarding the expressed opinion regarding the differences between the Romanian system and the external system regarding the imposed organizational boundaries, their strictness as well as the sanctioning area of deviations.

Fortunately for the Romanian public institutions, the hypothesis was not confirmed, the opinions expressed being very unfavorable to the hypothesis, the difference consisting in opinions classified as neutral, in the sense that there were answers in which the respondents stated that they did not have access to such information, their visits having other specific objectives. In other words, there are no notable and appreciable 
differences between codes of conduct in Romanian and cross-border institutions, the norms being somewhat similar.

However, we consider it very important to underline that although the respondents stated that they did not have access to this type of information, they considered that at a glance, things seemed to work and that the members of those organizations were remarked by professionalism.

At the same time, it was underlined that with the help of the IT components, in the respective European countries the bureaucracy is very low and that even the Romanian public institutions have already taken important steps in this direction. One person made a comment at the expense of Romanian organizations, in that it highlighted the fact that political influences affect the proper implementation of ethics and professional conduct.

The statement of the no. 4 hypothesis is as follows: "Employee motivation is the manager's art to influence their behavior, in order to satisfy individual interests and achieve the expected results at the organizational level."

The method used is illustrated by Hume, known as Hume's causality model, meaning that if the first object was not (the first object X), the second would not exist ( $\mathrm{Y}$ - the second object).

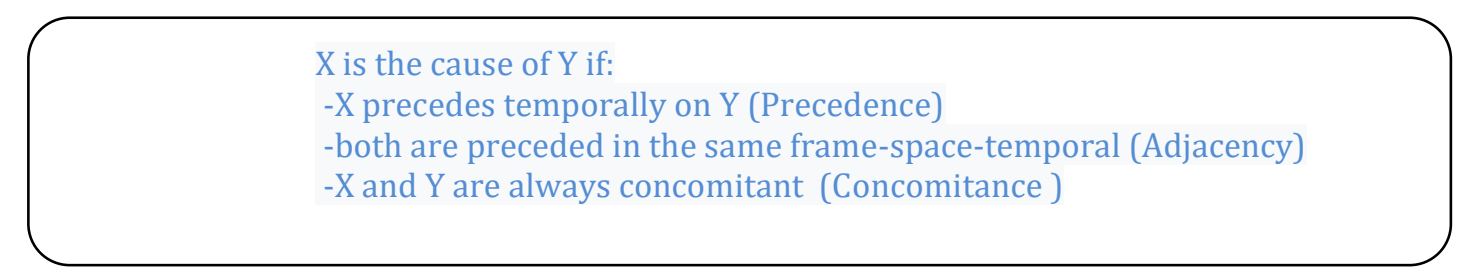

Figure no.2. Causality report regarding motivation of employees

Source: Own translation of the authors from https://adriandusa.eu/files/2014-EAC.pdf, last accessed 2019/06/28.

By analyzing the answers to the questionnaires and considering that $\mathrm{Y}$ is the motivated staff within an organization, $\mathrm{X}$ appeared to have one or more configurations, namely: X1 - Ensuring good working conditions, X2 - Good communication, X3 - Financial advantages, X4-Personal Development and Career Development Option, X5-Creating an Organizational Culture to Empower Employees' Talent and Outstanding Outcomes and X6-Job Safety, X7- Facilitating employee work by using IT tools.

The last hypothesis examined, hypothesis no. 5 concerns the concept of happiness / satisfaction at work, being stated as follows: "Foreign employees are happier at work, feeling appreciated and not stressed during their work time".

In order to determine the truth value of this hypothesis, we also used the QCA algorithm (comparative-qualitative analysis) using quantitative aggregate data to perform structural comparisons.

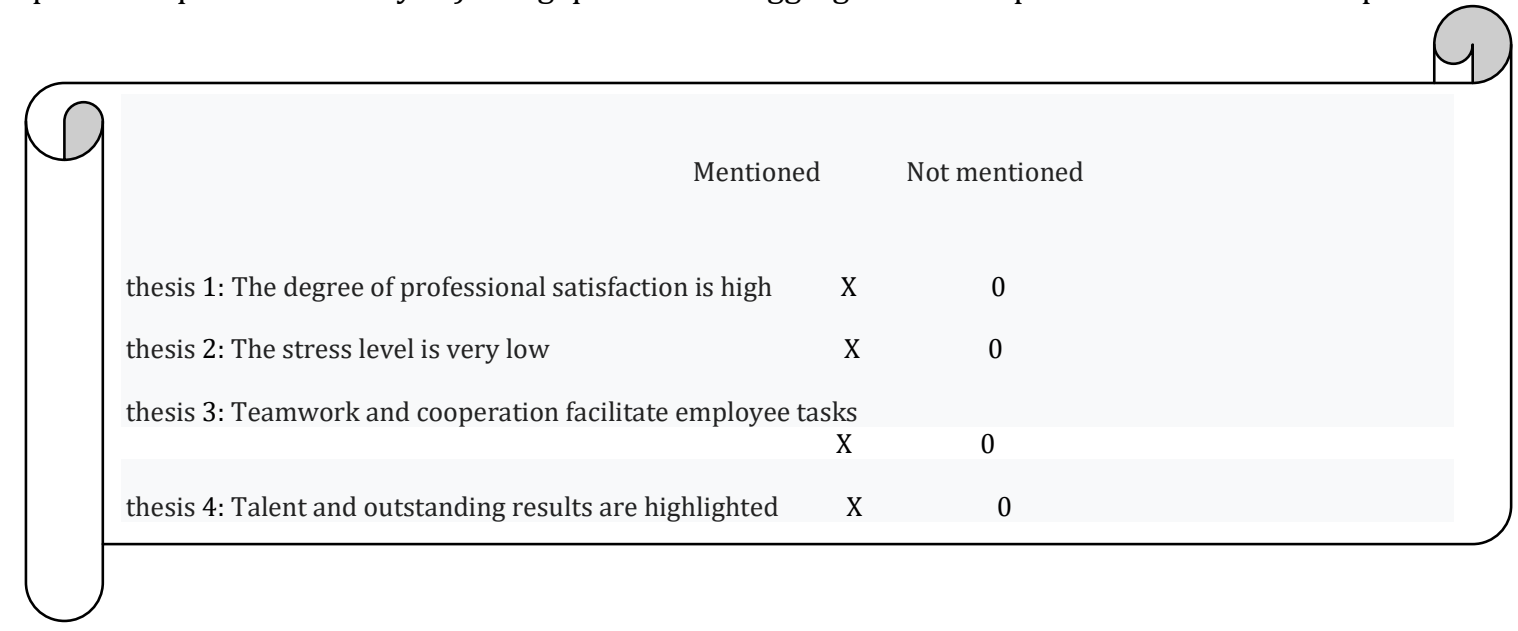

Figure no.3. Perception about happiness at work

Source: Own research of the authors

The working hypothesis was confirmed, Romanian employees being convinced of the level of increased satisfaction at the work place of foreign citizens. However, one of the respondents stated that it can not say whether foreign employees are happier at work or just adopt the appropriate professional attitude that any official in the public institutions should have, (essentially, the task of civil servants is to be in the service of the citizens). 


\section{Conclusions}

Consequently, in view of the elements revealed by the literature and taking into account the management practice of the Romanian organizations, in order to align the companies with the European standards, we believe that specific management strategies must be adopted so as to increase the trust of the citizens in the institutions (by providing quality public services in a shorter timeframe) and making Romanian employees happier at work by ensuring a fair balance between work and personal life (but also through respect and recognition of values and decent levels of pay and appropriate working conditions).

\section{References}

1. Collins, C., Smith, K., 2006, Knowledge exchange and combination: the role of human resource practices in performance of high-technology firms, The Academy of Management Journal,

https://www.researchgate.net/publication/234021442_Knowledge_Exchange_and_Combination_The_Role_of_Human_Resource_Practices_in _the_Performance_of_High-Technology_Firms, last accessed 2019/07/13;

2. Comisia Europeană, 2014, Cooperare internațională și dezvoltare, Luxemburg, Publicația Să înțelegem politicile Uniunii Europene, Oficiul pentru Publicatii al Uniunii Europene:

3. European Strategy Forum on Research Infrastructures, 2018, Innovation oriented cooperation of research infrastructures, Milano, Universita degli Studi di Milano;

4. European Commission, 2016, Working together to strengthen human capital, employability and competitiveness, Brussels;

5.Faria, P., Lima, F., Santos, Rui, S. 2010, Cooperation in innovation activities: The importance of parteners, Research Policy, https://www.researchgate.net/publication/222418574_Cooperation_in_innovation_activities_The_importance_of_partners, last accessed 2019/07/10;

6. Farr, H., Hosseingholizadeh, R., 2019, Aligning human resource management with knowledge management for better organizational performance: How to human resource practices support knowledge management strategies?, IntechOpen, https://www.intechopen.com/online-first/aligning-human-resource-management-with-knowledge-management-for-better-organizationalperformance-h, last accessed 2019/07/13;

7.Pinte, M., 2003, Omul în organizația sa, Revista Transilvană de Științe Administrative, IX;

8. Popescu, M., 2016, Managementul inovării, Brașov, Editura Universitătii din Brasov;

9.Schalk, R., Curșeu P., 2010, Cooperation in organizations, Journal of Managerial Psychology,

https://www.researchgate.net/publication/235323172_Cooperation_in_organizations, last accessed 2019/07/10.

10. Sienkiewicz, L., 2018, Human resource management: how to attract, retain and develop talent -Thematic Paper, Brussels, European Commission;

11.Stiles, P., Kulvisaechana, S., Human capital and performance: a literature review, Chambridge, The Judge Institute of Management, https://pdfs.semanticscholar.org/65f2/833e478cac47b5cdc8cb2b563e1da45ee08e.pdf, last accessed 2019/06/20. 